\title{
SELECTION ON PHAGOZYGOTIC ACTIVITY
}

\section{J. MEYER*, H. BUSCHMANN** and H. KRÄUSSLICH*}

(*) Institut f. Tierzucht und Tierhygiene

(**) Institut $f$. Medizinische Mikrobiologie, Infektions-

und Seuchenmedizin der Universität, München (B.R.D.)

In a two-day selection experiment mice lines with high and low carbon clearance rate were established. The estimates of realized heritabilities are 0.30 in the " high" "line and 0.25 in the "low" line. Correlated selection responses are discussed, especially spleen weight and tumor incidence.

EFFECTS OF SELECTION TO RESISTANCE ON NEWCASTLE DISEASE IN JAPANESE QUAIL,

\section{B. JAWOREK}

Institute of the Biological Basis of Animal Breeding, A gricultural University of Warsaw, Brwinow, Poland

Selection towards resistance of Japanese quail on Newcastle disease virus was carried out. Hemagglutination inhibition reaction titer was used as a selection factor.

Within new generations obtained greater resistance on virus ND infection was observed.

Considerably marked influence of low HI titers on incubation increase and mortality drop was observed after control infection. Essential differences of body weight appeared in selected and control groups of quails. Improvement in laying was not obtained.

\section{SYNDROME OF HEREDITARY TYROSINEMIA IN MINK}

\section{K. CHRISTENSEN, O. VENGE and H. S $\phi$ RENSEN}

Dep. of Animal Genetics, The Toyal Veterinary and Agricultural University, Bülowsvej $13, D K, I 870$ Copenhagen $V$

During the last few years some Danish mink farmers have observed a rather high frequency of death among kits of the Standard type. The deaths occur usually when the kits are about 6 weeks old, i. e. about the weaning age. The state of health of the kits appears quite normal during sucking period. The affected kits die within two-three days after the first symptoms have been observed. Watery eyes are the first sign of the disease, followed by the sticking eyelids. Pathologic-anatomical observations have been carried out. The most remarkable signs were oedematic kidneys. Cytological examinations showed no difference from the normal caryotype.

Biochemical investigations were performed on serum samples from normal and affected kits. These results demonstrated that the affected kits had 20-Ioo times higher plasma tyrosine concentrations than those found for normal kits. Also unusual high concentrations of the carboxylic acids derived from tyrosine were observed, corresponding to a defect in the enzyme 4-hydroxyphenylpyruvate dioxygenase. The plasma concentrations of the other proteini amino acids were less, but significantly altered whereas this was not the case for $\mathrm{Na}, \mathrm{K}, \mathrm{Ca}, \mathrm{and} \mathrm{Mg}$. It should be mentioned that the concentration of urea and creatinine was found 2-5 times higher in affected kits compared to normals.

Investigation concerning the genetics of the disease confirmed the hypothesis of a simple (Mendelian) recessive inheritance.

In conclusion the disorder is inherited as a recessive character, due to homozygosity at a single locus. No indication of pleiotropic effect, coupling between genes, etc. has been observed.

These results concerning the hereditary disease among mink show a parallelism to the hereditary disease in man known as hereditary tyrosinemia or hereditary tyrosinosis. 